\title{
Objetivos de seleção para sistemas de produção de gado de corte em pasto: ponderadores econômicos
}

\author{
[Economic values for breeding goal traits for Brazilian beef cattle production] \\ T.C.C. Bittencourt ${ }^{1}$, R.B. Lôbo $^{2}$, L.A.F. Bezerra ${ }^{2}$ \\ ${ }^{1}$ Departamento de Produção Animal - UFBA \\ Avenida Ademar de Barros, 500 \\ 40171-110 - Salvador, BA \\ ${ }^{2}$ Faculdade de Medicina de Ribeirão Preto - USP - Ribeirão Preto, SP
}

\begin{abstract}
RESUMO
Foram desenvolvidos objetivos de seleção para gado de corte criado nas condições de produção típicas do Brasil Central. As características consideradas foram: número de bezerros desmamados por vaca/ano (NBD), peso da carcaça (PC), peso à desmama (PD) e consumo de alimento. Foram adotados dois sistemas de produção, um que considerava somente a cria e outro, o ciclo completo (cria, recria e engorda). No primeiro, as receitas foram a venda de bezerros à desmama, novilhas excedentes e vacas de descarte. No segundo, a receita foi a venda das novilhas excedentes, vacas de descarte e novilhos para o abate. Em ambas as situações, o lucro (USD/vaca/ano) foi estimado pela diferença entre receita e despesa. Os valores econômicos estimados foram expressos em dólar por unidade de mudança na característica, calculados na base vaca/ano. O valor econômico foi calculado avaliando-se a alteração ocorrida no lucro quando a característica era incrementada de uma unidade, permanecendo as demais inalteradas. A característica que apresentou maior valor bruto do ponderador econômico foi o NBD, seguida pelo consumo, PC e PD. Quando se considerou o valor econômico, em unidades de desvio-padrão genéticoaditivo, a ordem de importância foi consumo, PC, NBD e PD.
\end{abstract}

Palavras-chave: bovino de corte, objetivo de seleção, ponderador econômico

\begin{abstract}
Breeding objectives were developed for beef cattle production under typical economic and environmental conditions of central Brazil. The traits considered were: calves weaned per cow/year (NCW), weaning weight (WW), carcass weight (CW) and food intake. In the study, two systems were examined, a cowcalf system (surplus calves sold after weaning) and a cow-calf enterprise (in which surplus calves are raised for slaughter). In the first, income is from the sale of male calves and surplus heifers after weaning and of culled cows. In the second, the income is from the sale of steers, surplus heifers and culled cows. For both situations, the profit (US\$/cow/year) was estimated by the difference between revenue and costs. The economical values (EV) were calculated as the change in profit resulting from a unit change in each trait, as other traits remained unchanged. The trait with greatest economic value was NCW, followed by food intake, CW and WW. The order of importance when values were in additive genetic standard deviation units were feed intake, $\mathrm{CW}, \mathrm{NCW}$ and WW.
\end{abstract}

Keywords: beef cattle, breeding objective, economic value

Recebido em 7 de outubro de 2003

Aceio em 20 de dezembro de 2005

E-mail: calmon@ufba.br 


\section{INTRODUÇÃO}

O objetivo do melhoramento genético animal é aumentar a freqüência de combinações gênicas favoráveis a um conjunto de características relacionadas a um dado sistema de produção, tendo como conseqüência $\mathrm{o}$ incremento da eficiência econômica, que é determinado, em parte, pela ênfase relativa das características incluídas nos objetivos de seleção (Smith, 1983).

A definição dos objetivos de seleção deveria ser o primeiro passo na elaboração de um programa de melhoramento genético (Urioste et al., 2000). $\mathrm{O}$ objetivo de seleção ou genótipo agregado $(\mathrm{H})$ pode ser definido como a combinação de características economicamente importantes, devendo ser levadas em consideração todas aquelas que influenciam a receita e a despesa. Sua definição é um problema de natureza econômica e não genética (Ponzoni, 1992) e espera-se que a resposta à seleção seja maior, em unidades monetárias, se os indivíduos forem ordenados pelo genótipo agregado (Weller, 1994).

Após a definição dos objetivos, são escolhidas as características e/ou os critérios de seleção, a partir dos quais serão feitas as predições dos valores genéticos dos indivíduos. As características consideradas nos objetivos de seleção são a base para a formulação da função lucro a partir da qual são derivados os ponderadores econômicos (Vercesi Filho, 1998), que podem ser definidos como o retorno econômico adicional por unidade de melhoramento na característica (Cameron, 1997).

No Brasil existem vários programas de melhoramento que realizam avaliações genéticas periódicas de um grande número de animais, sendo inegável a qualidade das avaliações genéticas realizadas por esses grupos. Deve-se a eles, parcialmente, a revolução que se observou na pecuária seletiva do Brasil na década de noventa. Contudo, a despeito da crescente preocupação com a eficiência econômica dos sistemas de produção, são muito poucos os estudos que propõem o estabelecimento de objetivos de seleção que maximizem sua lucratividade. Com objetivos claros, é possível avaliar, com um mínimo de erro, os valores econômicos associados a cada componente da resposta e, assim, escolher quais características devem ser incluídas no programa de melhoramento.

Os objetivos deste estudo foram: estabelecer objetivos de seleção que tenham como conseqüência maximizar a eficiência econômica de sistemas de produção de gado de corte em pasto, estimar os ponderadores econômicos das características incluídas nos objetivos de seleção e avaliar o efeito de situações alternativas de produção e preço sobre os ponderadores econômicos.

\section{MATERIAL E MÉTODOS}

$\mathrm{Na}$ determinação dos objetivos de seleção, utilizou-se metodologia proposta por Ponzoni e Newman (1989). Foram desenvolvidos objetivos para dois sistemas de produção, um dedicado somente à cria (sistema 1) e outro que realiza o ciclo completo: cria, recria e engorda (sistema 2 ).

Para especificação do sistema de reprodução, produção e comercialização, considerou-se um rebanho comercial típico com número fixo de 1000 matrizes da raça Nelore em reprodução, incluindo novilhas de 24 meses. Na Fig. 1, observa-se a composição do rebanho. Essa informação é necessária para que se identifique a composição etária e numérica do rebanho, o número de animais necessários para reposição e o número de animais disponíveis para comercialização, usados no cálculo dos ponderadores econômicos.

Assumiu-se que as novilhas são colocadas na estação de cobrição aos 24 meses de idade, resultando em idade ao primeiro parto em torno de 36 meses. O período de acasalamento iniciase em outubro e tem duração de 90 dias. A estação de cobrição das novilhas começa 60 dias antes da estação das vacas. Os bezerros permanecem a pasto com as mães e são desmamados, em média, com 8 meses de idade, no mês de abril. No rebanho dedicado exclusivamente à cria, todos os bezerros machos são vendidos até um ano de idade, e as fêmeas excedentes são comercializadas após a estação de monta. No rebanho de ciclo completo, machos e fêmeas excedentes vão diretamente para o abate. Em ambas as situações, todos os animais são mantidos exclusivamente a pasto durante toda sua vida, recebendo apenas sal mineral. 


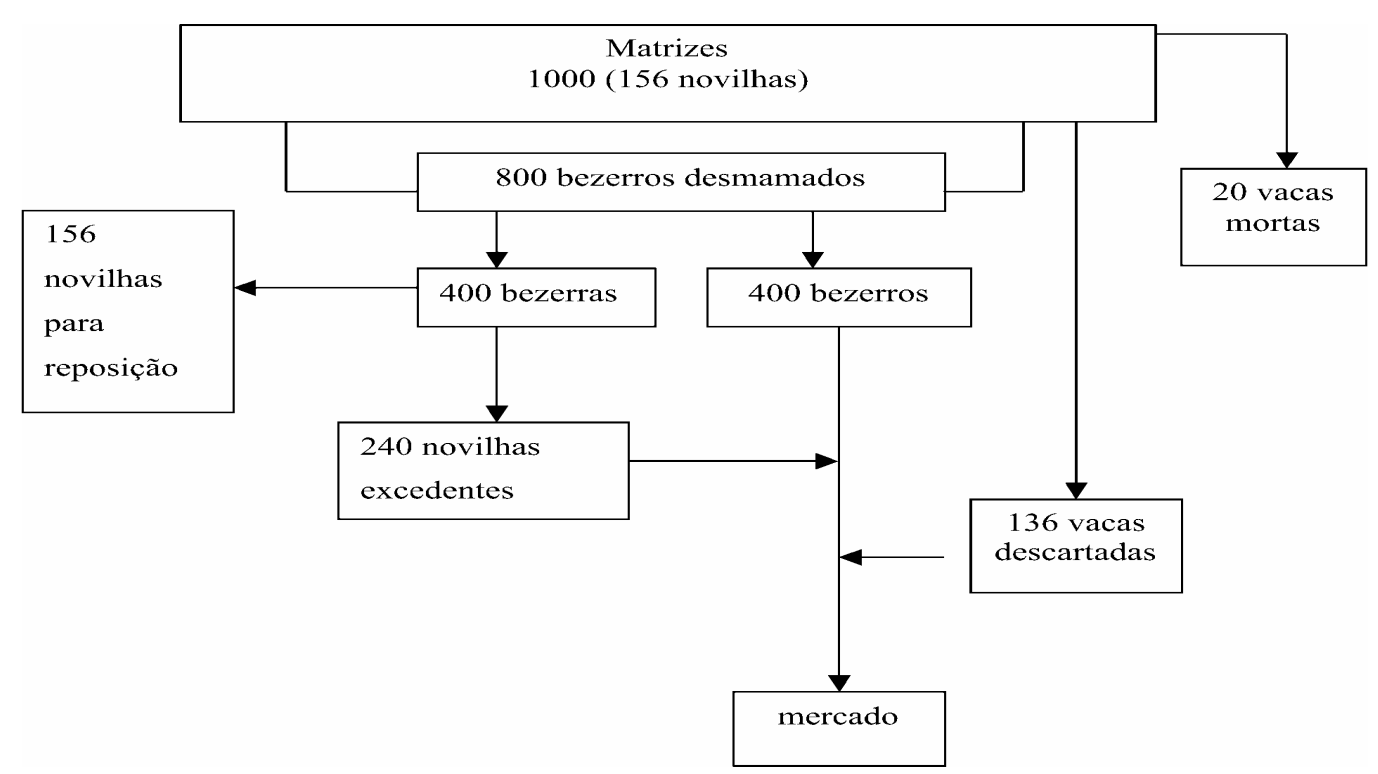

Figura 1. Composição do rebanho usado para especificação do sistema de reprodução, produção e comercialização.

Considerou-se que a quantidade de alimento disponível é variável durante todo o ano e capaz de assegurar um número fixo de fêmeas em reprodução dentro do rebanho e ganho de peso necessário para atingir os índices propostos. $\mathrm{Na}$ Tab. 1, são apresentados os índices de produtividade considerados nos cálculos dos ponderadores econômicos.

A identificação das origens das receitas e das despesas permite o desenvolvimento das equações de lucro, em que o lucro (L) é uma função das receitas $(\mathrm{R})$ e dos custos $(\mathrm{C}): \mathrm{L}=\mathrm{R}-\mathrm{C}$.

Neste estudo, as receitas são resultado da soma do produto entre o número de animais comercializados dentro de cada classe pelo seu valor de mercado. No sistema 1, são fontes de receita a venda de bezerros machos, novilhos excedentes e vacas de descarte; no sistema 2, constituem fontes de receita a venda de novilhos para o abate, novilhas excedentes e vacas de descarte.

Tabela 1. Índices zootécnicos e de desempenho considerados nos cálculos dos ponderadores econômicos

\begin{tabular}{|c|c|c|}
\hline Característica & Unidade & Quantidade \\
\hline Número de bezerros desmamados (NBD) ${ }^{1}$ & $\%$ & 0,8 \\
\hline Peso de abate (machos) & $\mathrm{kg}$ & 450 \\
\hline Peso da carcaça do novilho $\left(\mathrm{PC}_{\mathrm{no}}\right)$ & $\mathrm{kg}$ & 243 \\
\hline Peso da carcaça da novilha $\left(\mathrm{PC}_{\mathrm{na}}\right)$ & $\mathrm{kg}$ & 183 \\
\hline Peso da carcaça da vaca $\left(\mathrm{PC}_{\mathrm{va}}\right)$ & $\mathrm{kg}$ & 225 \\
\hline Taxa de mortalidade após desmama & $\%$ & 2,0 \\
\hline Rendimento da carcaça ${ }^{2}$ & $\%$ & 54 \\
\hline Peso à desmama ${ }^{3}(\mathrm{PD})$ & $\mathrm{kg}$ & 175 \\
\hline Peso das vacas à idade adulta ${ }^{4}$ & $\mathrm{Kg}$ & 452 \\
\hline Consumo voluntário de matéria seca (CVMS kg/100kg PV/dia) ${ }^{5}$ & $\mathrm{~kg}$ & 2,5 \\
\hline
\end{tabular}

${ }^{1}$ Newman et al. (1992); ${ }^{2}$ Rocha (2001); ${ }^{3}$ média geral de ambos os sexos (Bezerra, 2001); ${ }^{4}$ Schwengber (2001); ${ }^{5}$ Genro et al. (1999). $\mathrm{PV}=$ peso vivo.

\footnotetext{
${ }^{1}$ Rocha, C.E. Ribeirão Preto, SP, Brasil. 2001. Comunicação pessoal.
} 
Partindo de um sistema de produção a pasto, com gado Nelore, monta natural no período outubro janeiro, nascimentos de julho a setembro e desmama no mês de abril, imputaram-se custos com alimentação e com práticas normais de manejo (vacinação, vermifugação, mineralização e administrativos). Esses são considerados custos variáveis e estão relacionados com o nível de produtividade do rebanho. Os custos fixos são aqueles chamados de irreversíveis, tais como: arrendamento de terra, aluguel de equipamento, juros de empréstimos, salário de empregados com contratos de longo prazo etc. Eles têm que ser suportados mesmo que a propriedade não produza nada e não se alteram, ainda que a quantidade produzida se modifique (Samuelson e Nordhaus, 1993). Neste estudo, os custos fixos foram ignorados, já que o lucro anual foi obtido pela diferença entre receitas e despesas, e os termos que não envolvem as características consideradas nos objetivos de seleção desaparecem quando é obtida a derivada parcial da equação de lucro (L) com respeito a cada característica (Ponzoni e Newman, 1989).

Na Tab. 2, são apresentados os preços e os custos considerados neste estudo e que influenciaram o lucro nos rebanhos. Todos os preços foram expressos em USD.

Tabela 2. Preços e custos médios usados para composição das equações de lucro, em USD

\begin{tabular}{lcc}
\hline Característica & Unidade & Valor \\
\hline Receitas - Rebanho 1 & $\mathrm{kg}$ & $0,73^{1}$ \\
Venda de bezerros à desmama & $\mathrm{kg}$ & $1,19^{1}$ \\
Venda de novilhas excedentes, aos 24 meses & $\mathrm{kg}$ & $1,19^{1}$ \\
Venda de vacas de descarte & $\mathrm{kg}$ & $1,39^{1}$ \\
Receitas - Rebanho 2 & $\mathrm{kg}$ & $1,19^{1}$ \\
$\quad$ Venda de novilhos para abate & $\mathrm{kg}$ & $1,19^{1}$ \\
Venda de novilhas excedentes, aos 24 meses & \\
Venda de vacas de descarte & USD & 11,00 \\
Despesas & USD & 0,0067 \\
Custo com práticas gerais de manejo por cabeça/ano (vacinação, vermifugação, sal mineral, outros) \\
Custo de 1kg de MSV de pastagem &
\end{tabular}

O lucro foi expresso em função das características biológicas que tiveram impacto sobre as receitas e as despesas (Tab. 3). De acordo com Morris (1980), as características que determinam a eficiência biológica e econômica da produção de gado de corte são o peso da carcaça e o número de bezerros desmamados por ano. Como a maior parte do alimento disponível é utilizado para manutenção das vacas, o aumento do número de bezerros causa redução dos custos por bezerro, pois dilui os custos de mantença por um número maior de indivíduos.

Foram escolhidos como objetivos de seleção: o número de bezerros desmamados por vaca/ano (NBD), o peso à desmama (PD) e o peso da carcaça (PC). No Brasil, é necessário que os custos com a mantença dos animais permaneçam relativamente baixos e que o aumento da produção não se dê às expensas do aumento das exigências nutricionais e do consumo. Para que se monitore o efeito do aumento das demais características sobre os custos de produção, mais especificamente, o custo com alimentação, incluiu-se o consumo entre os objetivos de seleção.

Apesar de estarem incluídas nos objetivos de seleção características que avaliam a qualidade da carcaça e que poucos frigoríficos, no Brasil, remuneram as características de melhor qualidade, optou-se por considerar apenas o peso dessas. 
Tabela 3. Características biológicas que influenciam os custos e as receitas, incluídas nos objetivos de seleção segundo os sistemas de criação

\begin{tabular}{|c|c|}
\hline Produto ou atividade & Característica \\
\hline & Sistema 1 \\
\hline Venda de bezerros até 1 ano & $\begin{array}{l}\text { Número de bezerros desmamados (NBD), peso à desmama (PD), número de } \\
\text { bezerros desmamados (NBD) }\end{array}$ \\
\hline Venda de novilhas excedentes & Número de bezerros desmamados (NBD), peso da carcaça $\left(\mathrm{PC}_{\mathrm{na}}\right)$ \\
\hline Venda de vacas de descarte & Peso da carcaça $\left(\mathrm{PC}_{\mathrm{va}}\right)$ \\
\hline Alimentação & Consumo (bezerros, novilhas, vacas),. NBD \\
\hline Insumos & NBD \\
\hline & Sistema 2 \\
\hline Venda de novilhos para abate & Número de bezerros desmamados (NBD), peso da carcaça $\left(\mathrm{PC}_{\mathrm{na}}\right)$ \\
\hline Venda de novilhas excedentes & Número de bezerros desmamados (NBD), peso da carcaça $\left(\mathrm{PC}_{\mathrm{na}}\right)$ \\
\hline Venda de vacas de descarte & Peso da carcaça $\left(\mathrm{PC}_{\mathrm{va}}\right)$ \\
\hline Alimentação & Consumo (novilhos, novilhas, vacas), NBD \\
\hline Insumos & NBD \\
\hline
\end{tabular}

Sistema 1 = dedicado somente à cria; sistema 2 = dedicado ao ciclo completo: cria, recria engorda.

Na derivação dos ponderadores econômicos, o lucro foi expresso em função das características incluídas nos objetivos de seleção, e os termos foram agrupados por classe de gado, calculando- se custos e receitas em um ano de produção.

Cada termo foi expresso em função das características dos objetivos de seleção:

$$
\begin{aligned}
& L=L_{\text {bezerros }}+L_{\text {novilhas }}+L_{\text {vacas }}+L_{\text {novilhos }}-\text { custos fixos } \\
& L_{\text {bezerros }}=0,5 \times N \times N B D\left[(P D \times 0,73)-\left(\left(2 \times C O_{b e} \times 0,0067 \times 185\right)-(2 \times 11,00)\right)\right] \\
& L_{n o v i l h a s}=0,5 \times N \times N B D\left[\left(\mathrm{PC}_{\mathrm{na}} \times 1,19\right)-\left(C O_{n a} \times 0,0067 \times 365\right)-11,00-156 / 400\left(P C_{n a} \times 1,19\right)\right] \\
& L_{\text {vacas }}=N\left[136 / 1000\left(P C_{n a} \times 1,19\right)-\left(C O_{n a} \times 0,0067 \times 365\right)-11,00\right] \\
& L_{n o v i l h o s}=0,5 \times N \times N B D\left[\left(P C_{n o} \times 1,39\right)-\left(C O_{n o} \times 0,0067 \times 365\right)-11,00\right],
\end{aligned}
$$

em que:

$L_{\text {bezerros, }} L_{\text {novilhas }}, L_{\text {vacas }}$ e $L_{\text {novilhos }}=$ parte do lucro atribuído aos bezerros, novilhas, vacas e novilhos, respectivamente; $\mathrm{N}=$ número de matrizes em reprodução; $\mathrm{NBD}=$ número de bezerros desmamados; $\mathrm{PD}=$ peso à desmama; $\mathrm{CO}_{\mathrm{be}}, \mathrm{CO}_{\mathrm{na}}, \mathrm{Co}_{\mathrm{va}}$ e $\mathrm{CO}_{\mathrm{no}}=$ consumo voluntário de matéria seca de bezerros, novilhas, vacas e novilhos, respectivamente; $\mathrm{PC}_{\mathrm{na}}, \mathrm{PC}_{\mathrm{va}}$ e $\mathrm{PC}_{\mathrm{no}}=$ peso da carcaça de novilhas, vacas e novilhas, respectivamente.

As receitas do sistema de produção levaram em conta que uma parte das novilhas retorna ao rebanho de cria para repor as vacas descartadas. Para tal, foi adicionado um termo à equação que expressa o lucro obtido com as novilhas e que reflete o fato de que 156 das 400 novilhas disponíveis são incorporadas ao rebanho de cria após a primeira estação de monta. Da mesma forma, as receitas obtidas com a venda de vacas de descarte foram multiplicadas por 0,136 (136/1000), que é a proporção das vacas descartadas anualmente. Considerou-se que a mortalidade após a desmama foi de $2 \%$. Contudo, para simplificar os cálculos e, após verificar que o efeito desse valor sobre $o$ ponderador econômico era desprezível, adotouse taxa de mortalidade zero para essa fase.

Os ponderadores foram obtidos pela diferenciação da equação de lucro em relação a cada uma das características. A derivada foi depois calculada usando-se a média dos valores do desempenho nas outras características (Moav e Hill, 1996), de maneira que apenas os termos relacionados com a característica foram considerados. O ponderador econômico de uma característica é a mudança no retorno líquido por unidade de mudança na característica. 
Como as características não se expressam todas ao mesmo tempo na vida do indivíduo, nem com a mesma freqüência, os ponderadores econômicos, calculados a partir de uma equação com base na diferença entre receita e custos anuais, apresentam o problema de sobrestimar o valor econômico de caracteres que se expressam mais tarde na vida do animal e de subestimar os que se expressam mais cedo (Ponzoni $\left.{ }^{2}, 2001\right)$.

Foram estudados os efeitos de situações alternativas de produção e preço sobre os ponderadores econômicos. Avaliaram-se os efeitos da variação do preço da carne (aumento $20 \%$; redução 20\%), do peso dos animais (aumento 20\%; redução 20\%), do preço do kg de matéria seca de pasto (redução de 20\%, 30\% e $50 \%$ ) e do consumo (aumento $20 \%$; redução $20 \%$ ).

\section{RESULTADOS E DISCUSSÃO}

$\mathrm{Na}$ Tab. 4, são apresentadas as características incluídas nos objetivos de seleção e seus respectivos valores econômicos (VE), em valores absolutos $(\$)$ e padronizados $\left(\mathrm{VE} \times \sigma_{\mathrm{a}}\right)$. São expressos em dólar por unidade de mudança na característica e foram calculados na base vaca/ano. Como sua magnitude é influenciada pela unidade de medida escolhida (ex.: g ou kg), podem não dar uma boa indicação da importância relativa da característica. $\mathrm{O}$ produto do valor econômico pelo desvio-padrão genéticoaditivo $\left(\sigma_{\mathrm{a}}\right)$ fornece uma idéia da variação genético-econômica disponível para seleção e independe da unidade em que as características são expressas, sendo um bom indicador da importância relativa da variável (Ponzoni e Gifford, 1990).

$\mathrm{Na}$ Tab. 5, estão as estimativas de herdabilidade e os desvios-padrão fenotípicos usadas para o cálculo do desvio-padrão genético-aditivo. Os valores utilizados são provenientes de estudos com a raça Nelore, realizados pelo Grupo GEMAC do Departamento de Genética da
USP/Ribeirão Preto (Bezerra, 2001) ${ }^{3}$. Quando não havia estimativas de certas características na raça Nelore, usaram-se parâmetros estimados na Austrália e na Nova Zelândia (Ponzoni e Newman, 1989; Newman et al., 1992) com outras raças ou utilizaram-se parâmetros indicados por Heimerink (2000).

A característica que exibiu a maior variação genético-econômica no sistema 1 foi o consumo; no sistema 2, a carcaça. A presença de variação genético-econômica não significa, necessariamente, que a característica possa ser usada, já que a predição do valor genético pode ser mais difícil para uma característica do que para outra. Na prática, a contribuição de cada característica para o ganho genético-econômico global vai depender não só da disponibilidade de variação genético-econômica, mas também da acurácia com que o valor genético da característica em questão possa ser predito (Ponzoni, 1992).

A característica que apresentou maior valor bruto do ponderador econômico foi o NBD. Resultado semelhante foi obtido por Newman et al. (1992), ao verificarem que o ponderador econômico do NBD apresentava valor 200 vezes maior que o do peso da carcaça.

No sistema 2, atribuiu-se valor zero ao ponderador econômico do PD, pois os animais são vendidos diretamente para o abate. Contudo, deve-se ressaltar a importância dessa característica, já que, quanto mais pesado for o bezerro na desmama, maior a probabilidade de alcançar o peso de abate mais cedo. No sistema 1, o ponderador do PD foi USD 0,29, o que significa que o aumento de $1 \mathrm{~kg}$ no peso do bezerro ao desmame resultaria em aumento de USD 0,29/vaca/ano no lucro.

O valor econômico do peso da carcaça foi USD 0,45 no sistema 1 e USD 1,00 no sistema 2. Esse resultado era esperado graças à maior importância do peso da carcaça em rebanhos que vendem os animais diretamente para o abate.

\footnotetext{
2 Ponzoni, comunicação pessoal, 2001, WorldFish Center, Penang, Malaysia.
}

\footnotetext{
3 Bezerra, L.F. USP, Ribeirão Preto, SP, Brasil. 2001. Comunicação pessoal.
} 
Tabela 4. Valor econômico (VE) e variação genético-aditiva em unidades econômicas (VE x $\sigma_{\mathrm{a}}$ ) das características do objetivo de seleção

\begin{tabular}{lcccc}
\hline \multirow{2}{*}{ Característica } & \multicolumn{2}{c}{ Sistema 1 } & \multicolumn{2}{c}{ Sistema 2 } \\
\cline { 2 - 5 } & VE & VE x $\sigma_{\mathrm{a}}$ & VE & $|\mathrm{VE}| \mathrm{x} \sigma_{\mathrm{a}}$ \\
\hline NBD (bezerros/vaca/ano) & 97,61 & 8,00 & 199,36 & 16,35 \\
Peso à desmama $(\mathrm{kg})$ & 0,29 & 2,07 & 0 & 0 \\
Peso da carcaça $(\mathrm{kg})$ & $0,45 \mathrm{~s}$ & 8,85 & 1,00 & 19,66 \\
Consumo $(\mathrm{kg} / \mathrm{MSV} / \mathrm{dia})$ & $-4,42$ & 15,43 & $-4,40$ & 15,36 \\
\hline
\end{tabular}

Sistema 1 = dedicado somente à cria; sistema 2 = dedicado ao ciclo completo: cria, recria engorda.

$\mathrm{NBD}=$ número de bezerros desmamados; MSV = matéria seca verde.

Tabela 5. Estimativas de desvio-padrão fenotípico $\left(\sigma_{\mathrm{p}}\right)$ e herdabilidade $\left(\mathrm{h}^{2}\right)$ usadas para o cálculo do desvio-padrão genético-aditivo das características incluídas nos objetivos de seleção dos sistemas 1 e 2

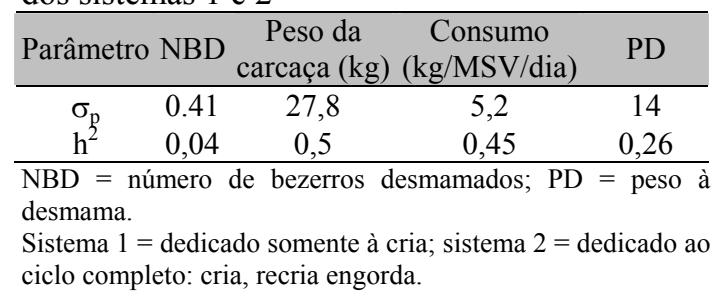

O consumo obteve valor econômico igual a $-4,4$ em ambos os sistemas de produção, o que implica que o aumento de $1 \mathrm{~kg}$ no consumo de MS de pasto provoca redução de cerca de USD 4,40 no lucro. Deve-se considerar que o aumento do consumo de alimentos ocorre para todas as categorias de animais.

A característica que apresentou maior sensibilidade dos ponderadores às alterações nas circunstâncias de produção avaliadas (Tab. 6) foi o número de bezerros desmamados/vaca/ano. Esse resultado era esperado, já que a característica influencia todas as origens de receitas e custos. Quanto mais bezerros forem produzidos, maior será a receita. Além disso, verifica-se a diluição dos custos de mantença das vacas entre maior número de animais.

Deve-se lembrar que o custo de manutenção das matrizes responde por cerca de $70 \%$ do custo com alimentação (Evans, 2003). O custo de manutenção de uma vaca que não produz um bezerro por ano é praticamente o mesmo da que produz. Esse resultado confirma a importância da seleção que visa ao aumento da eficiência reprodutiva do rebanho. Ainda que as características ligadas à reprodução apresentem, usualmente, herdabilidade baixa, elas têm grande impacto econômico. $\mathrm{O}$ valor econômico do NDB foi influenciado por todos os fatores estudados: preço da carne, peso do animal, custo do quilograma de matéria seca de pasto e quantidade de forragem consumida por dia, sendo os dois primeiros fatores os mais importantes. Modificações no consumo e no valor no quilograma de pastagem pouco influenciaram esse valor.

$\mathrm{O}$ valor econômico do PD foi influenciado apenas pelo preço da carne, resultado que sugere pequena influência atribuída ao desempenho do animal e ao preço do alimento, semelhante ao observado com o ponderador do peso da carcaça.

O valor econômico do consumo foi influenciado pelo valor do quilograma de matéria seca de pasto, como esperado. Variações no consumo só alteraram o valor econômico do NBD. Como essa influência foi pequena, pode-se concluir que a variação no consumo não alterou a importância relativa das características na determinação do lucro.

$\mathrm{O}$ preço da carne teve influência sobre os ponderadores econômicos do NBD, PD e PC. No sistema 1 , o aumento ou a diminuição de $20 \%$ no preço da carne resultou em variação de $26,7 \%$ no valor do ponderador do NBD e de $20 \%$ no do PD e PC. Esse resultado demonstra que a alteração no valor do produto modificou a importância econômica relativa das características NBD, PD e PC, mas não influenciou a do consumo sobre a lucratividade do sistema. 
Objetivos de seleção para sistemas de produção...

Tabela 6. Ponderadores econômicos (USD/vaca/ano) para as características do genótipo agregado e sua sensibilidade a mudanças no nível de produção e dos preços da carne e do quilograma de matéria seca de pasto

\begin{tabular}{|c|c|c|c|c|c|}
\hline Característica & \multicolumn{5}{|c|}{ Situação-base } \\
\hline & \multicolumn{2}{|c|}{ Sistema 1} & \multicolumn{3}{|c|}{ Sistema 2} \\
\hline NBD & \multicolumn{2}{|c|}{97,61} & \multicolumn{3}{|c|}{199,36} \\
\hline Peso à desmama (kg) & \multicolumn{2}{|c|}{0,29} & \multicolumn{3}{|c|}{0,00} \\
\hline Peso da carcaça (kg) & \multicolumn{2}{|c|}{0,45} & \multicolumn{3}{|c|}{1,00} \\
\hline \multirow[t]{3}{*}{ Consumo (kg/MSV/dia) } & \multicolumn{2}{|c|}{$-4,42$} & -4.40 & & \\
\hline & \multicolumn{5}{|c|}{ Preço da carne } \\
\hline & \multicolumn{2}{|c|}{ Sistema 1} & \multicolumn{3}{|c|}{ Sistema 2} \\
\hline & $20 \%$ redução & $20 \%$ aumento & $20 \%$ redução & $20 \%$ & tumento \\
\hline NBD & 71,55 & 123,67 & 152,30 & & 6,42 \\
\hline Peso à desmama (kg) & 0,23 & 0,35 & 0,00 & & 0,00 \\
\hline Peso da carcaça (kg) & 0,36 & 0,54 & 0,84 & & 1,21 \\
\hline \multirow[t]{4}{*}{ Consumo (kg/MSV/dia) } & $-4,42$ & $-4,42$ & $-4,40$ & & 4,40 \\
\hline & \multicolumn{5}{|c|}{ Peso do animal } \\
\hline & \multicolumn{2}{|c|}{ Sistema 1} & \multicolumn{3}{|c|}{ Sistema 2} \\
\hline & $20 \%$ redução & $20 \%$ aumento & $20 \%$ redução & $20 \%$ & umento \\
\hline NBD & 71,55 & 123,67 & 157,29 & & 1,43 \\
\hline Peso à desmama (kg) & 0,29 & 0,29 & 0,00 & & 0,00 \\
\hline Peso da carcaça $(\mathrm{kg})$ & 0,45 & 0,45 & 1,00 & & 1,00 \\
\hline \multirow[t]{4}{*}{ Consumo (kg/MSV/dia) } & $-4,42$ & $-4,42$ & $-4,40$ & & 4,40 \\
\hline & \multicolumn{5}{|c|}{ Redução do preço kg de MS de pasto } \\
\hline & \multicolumn{2}{|c|}{ Sistema 1} & \multicolumn{3}{|c|}{ Sistema 2} \\
\hline & $20 \%$ & $30 \%$ & $20 \%$ & $30 \%$ & $50 \%$ \\
\hline NBD & 100,84 & 105,70 & 204,20 & 206,81 & 209,41 \\
\hline Peso à desmama (kg) & 0,29 & 0,29 & 0,00 & 0,00 & 0,00 \\
\hline Peso da carcaça $(\mathrm{kg})$ & 0,45 & 0,45 & 1,00 & 1,00 & 1,00 \\
\hline \multirow[t]{4}{*}{ Consumo (kg/MSV/dia) } & $-3,53$ & $-3,09$ & $-3,55$ & $-3,09$ & $-2,63$ \\
\hline & \multicolumn{5}{|c|}{ Efeito do consumo } \\
\hline & \multicolumn{2}{|c|}{ Sistema 1} & \multicolumn{3}{|c|}{ Sistema 2} \\
\hline & $20 \%$ redução & $20 \%$ aumento & $20 \%$ redução & $20 \%$ & tumento \\
\hline NBD & 100,85 & 94,37 & 204,35 & & 9,87 \\
\hline Peso à desmama (kg) & 0,29 & 0,58 & 0,00 & &, 00 \\
\hline Peso da carcaça (kg) & 0,45 & 0,45 & 1,00 & & 1,00 \\
\hline Consumo (kg/MSV/dia) & $-4,42$ & $-4,42$ & $-4,40$ & & 1,40 \\
\hline
\end{tabular}

Sistema 1 = dedicado somente à cria; sistema 2 = dedicado ao ciclo completo: cria, recria engorda.

$\mathrm{NBD}=$ número de bezerros desmamados/vaca/ano; $\mathrm{MSV}=$ matéria seca verde; $\mathrm{MS}=$ matéria seca.

O peso do animal só teve influência sobre o valor econômico do NBD. A redução de $20 \%$ no peso de abate dos animais implicou redução de $26,7 \%$ no ponderador do NBD. As outras características não foram sensíveis à variação no peso do animal. Em rebanhos em que os animais são mais leves, a importância relativa do NBD sobre o lucro é menor do que naqueles em que os animais são mais pesados. A variação do peso, do consumo e do valor do alimento não alterou a importância econômica das outras características.

O preço do quilograma de pastagem foi responsável por variação no ponderador econômico do NBD e do consumo. A redução de $50 \%$ e $20 \%$ no preço do quilograma de matéria seca de pasto implicou alteração de $8,4 \%$ e 3,3\% no valor econômico do NBD, respectivamente. Ou seja, quanto mais barato o alimento, menor a influência relativa do seu preço sobre a lucratividade atribuída ao NBD. Com relação ao consumo, a influência do preço da pastagem foi grande e acompanhou a variação no preço. Quanto maior o custo com o pasto, maior a importância relativa do consumo sobre o retorno.

\section{CONCLUSÕES}

Os valores econômicos estimados foram razoavelmente robustos a mudanças nos preços da carne e do quilograma de matéria seca de pasto e no nível de produção. A característica na qual se observou maior sensibilidade dos 
ponderadores às alterações nas circunstâncias de produção foi $o$ número de bezerros desmamados/vaca/ano. A característica que teve maior impacto sobre a rentabilidade dos sistemas foi o número de bezerros desmamados.

\section{REFERÊNCIAS BIBLIOGRÁFICAS}

ANUÁRIO DA PECUÁRIA BRASILEIRA. São Paulo: FNP Consultoria \& Comércio, Argos, 2000. 391p.

CAMERON, N.D. Selection indices and prediction of genetics merit in animal breeding. Edimburgh: Reslin Institute, 1997. 208p.

EVANS, J.L. Genetic prediction of mature weight and mature cow maintenance energy requirements in red angus cattle. 2003. 318f. Thesis $(\mathrm{PhD})$ - Colorado State University, Fort Collins, Colorado.

GENRO, T.C.M.; PRATES, E.R.; HERRERO, M. et al. Estimativas de consumo de bovinos em pastejo utilizando duas formas de administração de $\eta$-alcanos como indicadores em gramíneas tropicais. Disponível em: $<\mathrm{http} / / / \mathrm{www}$.sbz.org.br /anais2000/Ruminantes/532.pdf $>$. Acessado em 20 de dezembro 2000.

HEIMERINK, J. Optimization of Nelore breeding programs in Brazil. 2000. 95f. Dissertação (Mestrado) - Wageningen Agricultural University, Wageningen.

MOAV, R.; HILL, W.G. Specialized sire and dam lines IV. Selection within lines. Anim. Prod., v.8, p.375, 1996.

MORRIS, C. A. Some benefits and costs of genetic improvement in New Zealand sheep and beef cattle industry. N. Zeal. Exp. Agric., v.8, p.331-340, 1980.

NEWMAN, S.; MORRIS, C.A.; BAKER, R.L. et al. Genetic improvement of beef cattle in New
Zealand: breeding objectives. Livest. Prod. Sci., v.32, p.111-130, 1992.

PONZONI, R.W. Genetic improvement of hair sheep in the tropics. Rome: FAO Animal Production and Health, 1992. (Paper, 101).

PONZONI, R.W.; GIDFFORD, D.R. Developing breeding objectives for Australian Cashmere goats. J. Anim. Breed. Genet., v.107, p.351-370, 1990.

PONZONI, R.W.; NEWMAN, S. Developing breeding objectives for Australian beef cattle production. Anim. Prod., v.49, p.35-47, 1989.

SAMUELSON, P.A.; NORDHAUS, W. Economia. 14.ed. Lisboa: McGraw-Hill, 1993.

SCHWENGBER, E.B. Produtividade acumulada e peso adulto como características alternativas na seleção de fêmeas da raça nelore. 2001. 113f. Tese (Doutorado). Faculdade de Medicina de Ribeirão Preto, Universidade de São Paulo, Ribeirão Preto, SP.

SMITH, C. Effects of changes in economic weight on the efficiency of index selection. $J$. Anim. Sci., v.56, p.1057-1064, 1983.

URIOSTE, J.J.; PONZONI, R.W.; AGUIRREZABAL et al. Breeding objectives for Uruguayan beef cattle production systems. In: WORLD CONGRESS ON GENETICS APPLIED TO LIVESTOCK PRODUCTION, 6., 2000, Armidale. Proceedings... Armidale: 2000. p.281-284.

VERCESI FILHO, A.E. Objetivos econômicos da seleção de gado de leite. In: SIMPÓSIO NACIONAL DE MELHORAMENTO ANIMAL, 2., 1998, Uberaba. Anais...Viçosa: UFV, 1998. p.135-145

WELLER, J.I. Economics aspects of animal breeding. Chapman \& Hall, 1994. 